\title{
Preliminary experimental evaluation of a novel loudspeaker featuring magnetorheological fluid surround absorber
}

\author{
Endra Dwi Purnomo ${ }^{1}$, Ubaidillah $^{2}$, Fitrian Imaduddin ${ }^{3}$, Iwan Yahya ${ }^{4}$, Saiful Amri Mazlan ${ }^{5}$ \\ ${ }_{1,2,3,4}$ Universitas Sebelas Maret, Indonesia \\ ${ }^{1}$ Balai Pengkajian dan Penerapan Teknologi (BPPT), Indonesia \\ ${ }^{2}$ National Center for Sustainable Transportation Technology (NCSTT), Indonesia \\ ${ }^{5}$ Malaysia Japan International Institute of Technology, Universiti Teknologi Malaysia, Malaysia
}

\begin{tabular}{l} 
Article Info \\
\hline Article history: \\
Received Jun 3, 2019 \\
Revised Aug 7, 2019 \\
Accepted Aug 21, 2019 \\
\hline
\end{tabular}

\section{Keywords:}

Damping force

Finite element

Loudspeaker

Magneto rheological fluids

Surround device

\begin{abstract}
A novel design of magneto rheological fluids (MRF) based surround device in a loudspeaker system was studied in this article. The main objective of this research is to design a new surround device of the loudspeaker that can be easily controlled its damping. Therefore, it was predicted that the audio pressure level on the loudspeaker could be easily manipulated at a different sound source by applying a certain magnetic field. This function could not be reached using one conventional speaker system. Firstly, a set of an electromagnetic device containing MRF was designed to replace the conventional rubber surround. The magnetic circuit was then evaluated using the finite element method magnetics to study the flux distribution in the MRF area. The current was varied from 0.25 to $0.75 \mathrm{~A}$ by an interval of $0.25 \mathrm{~A}$. The magnetic flux resulted from the simulation was then logged and used as the based value for predicting the change of shear yield stress. The base properties of the shear yield stress of the MRF against the magnetic flux was obtained from previous experimental result. Therefore, it was hopefully the prediction could be closed to the real system. Based on the simulation result, the shear yield stress varied from 43 to $49 \mathrm{Mpa}$ or about $15 \%$ increment. A simple experimental work was carried out. By applying particular direct current into the coil, the sound quality generated by the loudspeaker shows different values. Based on the preliminary experiment, the level of decibel decreased about $3 \mathrm{~dB}$ as the application of magnetic fields. The idea has been proven in this preliminary experimental evaluation.
\end{abstract}

Copyright () 2020 Institute of Advanced Engineering and Science. All rights reserved.

\section{Corresponding Author:}

Ubaidillah,

Department of Mechanical Engineering,

Universitas Sebelas Maret,

Jl. Ir. Sutami No.36 A, Pucangsawit, Kec. Jebres, Kota Surakarta, Jawa Tengah, 57126, Indonesia.

Email: ubaidillah_ft@staff.uns.ac.id

\section{INTRODUCTION}

Technologies utilizing magnetorheological fluids (MRFs) have been widely developing, and it has continued to grow over the past few decades. In general, the main applications of MRFs are for semi-active damping element in a vibration system, driving actuators, as well as the sensory system [1-7], seats of commercial vehicle [8, 9] high-speed trains suspension systems in [10, 11], large washing machine [12, 13], advanced artificial limb system [14, 15], aircraft landing gear [16, 17], automotive suspension systems [18-21], helicopter rotor system [22] complex mechanical systems [23], and so on. Existing research on the application of ferrofluid (not MRF) in the loudspeaker damping system is more focused on the main 
damping [2]. However, the speakers have sub-damping, i.e., surround [24, 25], Surround tends to work to help the spider work. This device is usually only attached to the loudspeaker basket and moves with a constant stiffness value based on its material properties [24, 26]. The loudspeaker must be accurate, strong, and smaller, with an increased acoustic quality [27].

To the best of author knowledge, implementation of MRF in a loudspeaker was rarely found [2]. Lee et al. [26] introduced a new type of speaker featuring MR foam. The MR foam was used to replace the existing surround. It was found that the sound pressure could be adjusted by varying the magnetic flux across the MR foam. However, this work did not provide a correct way of developing MR based devices. The magnetic circuit design was not evaluated properly.

This study contributes on the development of a novel device for replacing the surround of the loudspeaker to dampen the sub-damping spider featuring an MRF. The device was firstly designed, and its magnetic circuit was evaluated through finite element method magnetic resulting in a set data of magnetic flux across the MRF. The data were then used for predicting the changes in shear yield stress in which based on this alteration, the damping force in surround device can be altered. Simple experimental work is also provided to proof the concept idea.

\section{RESEARCH METHOD}

In this work, a new design of controllable loudspeaker base on surround damping system using MRF was proposed. The woofer type is selected as the base loudspeaker. The reason is the small working frequency range, compact woofer's size of the subwoofer type. The principle of the Lorenz force is due to the current generated from the voice coil. As a result of these styles, the cone can vibrate to cause sound [3]. So MRF fluid used to control the shear yield stress, surround held from damped frequency, then the loudspeaker frequency can change. Consequently, the pitch generated by the loudspeaker may vary. The new structural design of MRF surround is shown in Figure 1. The MRF surrounds device consists of four main parts, namely the cone, surround, O-ring, and coil that is needed technical considerations that are taken to develop the surround damping.

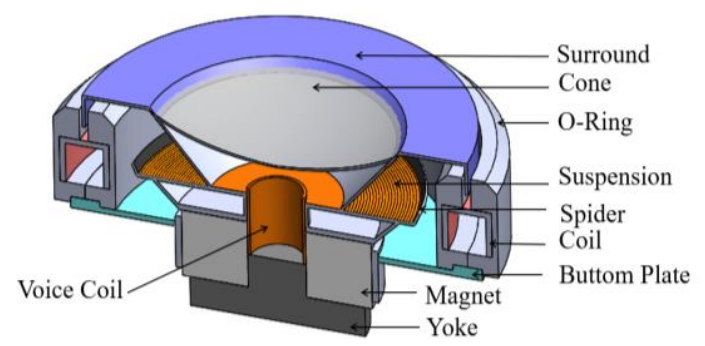

Figure 1. Design of MRF based surround structure

The cone has a large end, foldably connected to the frame, and a small end, aligned with the magnetic gap [4]. The surround is different with the existing design that forms a seating surface for an annular molded elastomeric ring has a generally semicircular cross-section $[24,26]$, the new surround design by flat plane cross-section with fin downwards to be able to accommodate the damping of MRF. The usefulness of O-Ring is to accommodate coil and overall attenuation to surround to be MR fluid device that can be controlled by current variations. The coil consists of a roll of copper wire wrapped in a lower Oring to distribute magnetic flux.

The principal of damping system in loudspeaker basically can be done by controlling MRF shear yield stress in the surround gap area. This technique is carried out by making changes of the surround resonant occurred frequency due to in viscosity of the MR fluid input electrical current to the coil [28]. Figure 1 shows that O-Ring was designed to accommodate the MRF container by two layers. The O-Ring casing resembles the outer shell of the surround with two main functions. The first function is to secure the whole structure of the MRF together as well as to connect the surround with MR fluid layers. The second function is to properly guide the magnetic flux from the coil so that the loss of flux to the air, which reduces the magnetic field intensity. The coil input generates the MRF's magnetic field to the thickness surround wall structure; the coil is turned in a coil bobbin that is also functioned as the wall of MRF surround structure. The geometry of the MRF surround device is explored in this study is shown in Figure 2, and the geometry of the surrounding structure shown in Table 1. 
Table 1. List of MRF Surrounds Geometry Parameter

\begin{tabular}{ccc}
\hline Parameter & Unit & Value \\
\hline$\eta$ ( MRF-132DG) & Pa s & 0.092 \\
$\mathrm{t} 1=\mathrm{t} 2=\mathrm{g}$ & $\mathrm{mm}$ & 1 \\
$\mathrm{t} 3$ & $\mathrm{~mm}$ & 5 \\
$\alpha$ ( O-Ring) & $\circ$ & 45 \\
$\beta$ ( Surround ) & $\circ$ & 130 \\
$\mathrm{~h} 1$ ( O-Ring) & $\mathrm{mm}$ & 38.35 \\
$\mathrm{~h} 2$ ( O-Ring) & $\mathrm{mm}$ & 4 \\
$\mathrm{~h} 3$ ( O-Ring) & $\mathrm{mm}$ & 9 \\
$\mathrm{~h} 4$ ( O-Ring) & $\mathrm{mm}$ & 14 \\
$\mathrm{~d} 1$ ( O-Ring) & $\mathrm{mm}$ & 21 \\
$\mathrm{~d} 2$ ( O-Ring) & $\mathrm{mm}$ & 10 \\
$\mathrm{~d} 3$ ( O-Ring) & $\mathrm{mm}$ & 5.5 \\
$\mathrm{~d} 4$ ( Bobin) & $\mathrm{mm}$ & 3.5 \\
\hline
\end{tabular}

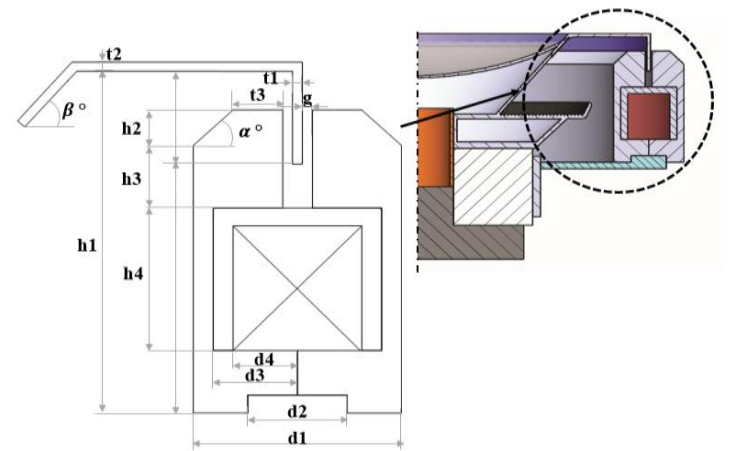

Figure 2. Dimension geometry

\subsection{Materials}

Material selection is significant support of the MRF of surround device performance that controlling the surround vibration. The O-ring, which, according to Figure 1, should be made from a magnetic material, is made from steel 1020. The surrounding material that used to damping the cone is used polyethylene. The last component, the coil windings consist by copper wire and an aluminum AISI 1100, bobbin, which has a structure and compact design by groove in circular wall. The surround damping device using specific MRF that is used in this study, an MRF made by Lord Corporation for general use in energy-dissipating, controllable, such as dampers [5]. The fluid consists of micron-sized magnetizable particles in the hydrocarbon fluid. The permeability of the MR fluid is acquired from the fluid manufacturer [6].

\subsection{Simulation Parameter}

Predictions on channel gaps are made to evaluate the performance of the loudspeaker before it was made. A finite element method (FEM) use to evaluate the magnetic field. The axisismetric 2D model be analys in this simulation method. An asymptotic boundary conditions have been applied. The coil set up to 546 turns of 23 AWG (American wire gauge) copper wire with the current input limited to 1,5 A, so the maximum power consumption of the MRF surround is $3.03 \mathrm{~W}$. The FEMM result is shown in Figures 3 and 4. Based on parametric calculations for the evaluation of the magnetic circuit voltage drop, flux linkage, inductance, resistance, and electrical power have been calculated. the two-dimensional (2D) axisymmetric meshed model shown in Figure 4. The element set up is a triangular element with a total number of elements 103771 and the total number of nodes 10089 .

The value yield stress for MRF-132DG, produced by Lord Corporation, is given in the form of a graph of yield stress versus magnetic field strength $\mathrm{H}$ [4], this information used to get an equation of yield stress using B value, by using a third-order polynomial approximation of the data available. As shown in (1) can be written as follows:

$$
\tau_{y}(B)=52.962 B^{4}-176.51 B^{3}+158.79 B^{2}+13.70+0.1442
$$

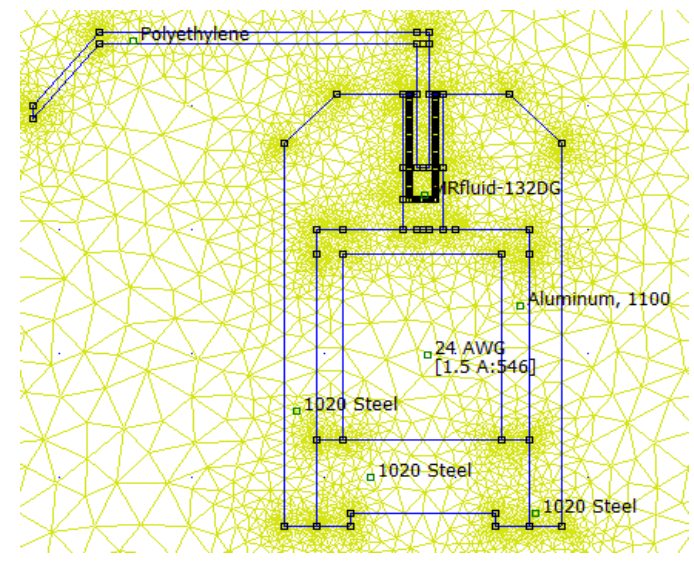

Figure 3. A meshed model of the surround 
The contour and flux lines of magnetic flux density for the whole magnetic circuit shown in Figure 4. The yield stress of MR fluid is only the flux that passed through the MR fluid zone. The Shear stress can be viewed in 2 loudspeaker layer channels in MRF gap diantara surround absorber which is zone 1, and zone 2. The magnetic flux of simulation was calculated to follow along with the line drawn in Figure 4. The MR fluid surround gap area is crossed by the magnetic flux. Figure 4 shows the path of magnetic flux at zone 1 and 2. It can be seen that the flux density varies from 0,6 to 1,7 $\mathrm{T}$ at 1,5 $\mathrm{A}$ applied current. The magnetic circuit design has exhibited a good flux distribution at the desired zones.

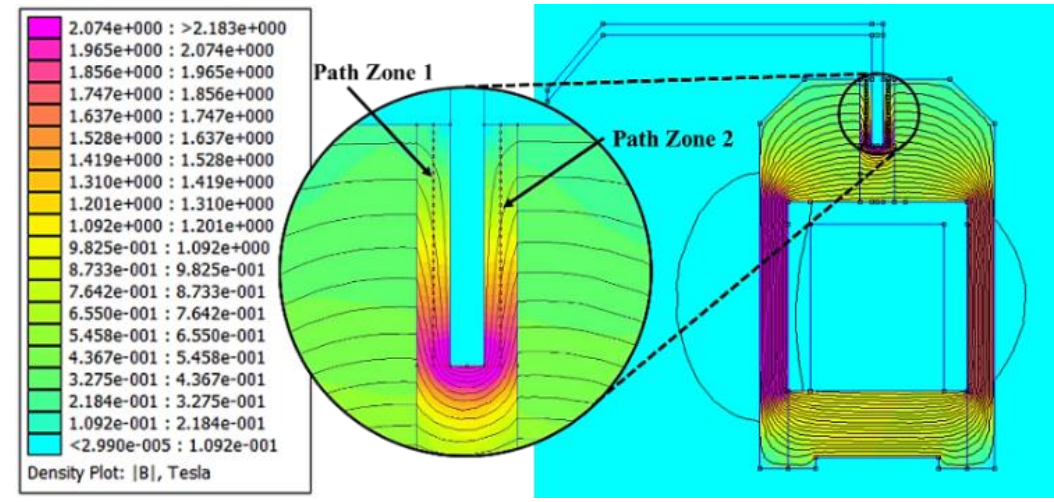

Figure 4. FEMM result of the flux density at 1,5 A current input

\section{RESULTS AND ANALYSIS}

\subsection{Simulation result}

Numerical simulation is the appropriate way for predicting the performance of magnetic circuit for this new device. The magnetic field strength of the proposed surround damping has been predicted by the FEMM analysis and has been applied in the yield stress. The magnetic flux density value at $0.25 \mathrm{~A}$ for zone 1 and 2 increases to be 0.78 , and $0,72 \mathrm{~T}$, respectively shwon in Figure 5. The magnetic flux density based on zone 1 and 2, increase to be 1,08 and 1,09 $\mathrm{T}$ at 1.5 A, respectively. The increased magnetic flux density changes in zone 2 at 0.75 A significantly increases from the flux changes in zone 1 . The MRF devices are normally represented and acceptable since fluxs density increases as proportional to the current $1.5 \mathrm{~A}$.

Figure 6 shows the flux distribution along the MRF chamber. The length indicates the distance from reference where the reference begins from the top of the chamber. It indicates that the depth of MRF chamber is $6 \mathrm{~mm}$. From the figure, it can be seen that the value of the flux density grows as the increase of the length. This is due to the fact that the deeper position, the closer to the coil. Moreover, the more current applied to the coil, it consequently increases the magnetic flux generated. The average value of flux density and length position were compared to know the different distribution of flux density in the gap. This value is influential against the damping force for the next investigation.

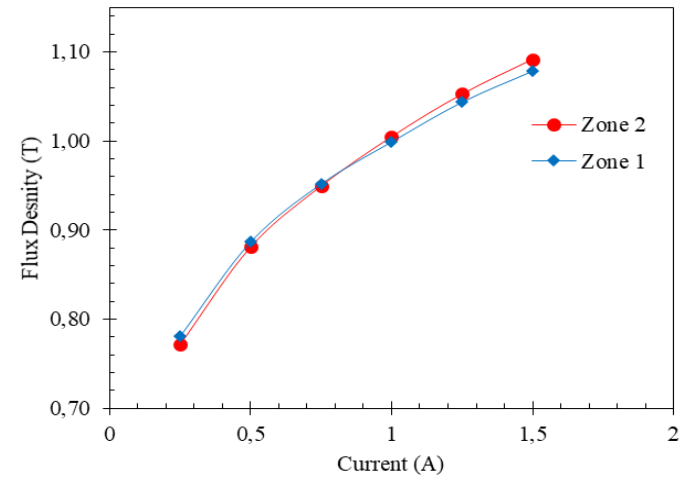

Figure 5. MRF of surround loudspeaker Flux Density

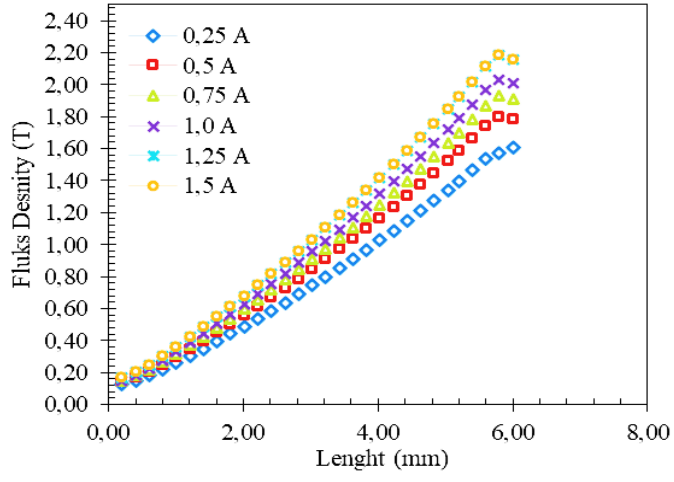

Figure 6. The Flux density distribution in path zone 1 


\subsection{Performance Prediction}

The boundary of properties had been made present clearly, and simulation setup results showed that shear yield stress applied for a significant increase in of a current 0.25 a to $1.5 \mathrm{~A}$. The increase was in nonlinear follow function over (1). The shear yield stress of MRF works in surround gap shown in Figure 7. The simulation results predict the shear yield stress increases as shown in Figure 7. The shear yield stress value at a current of 0.25 in zone 1 is 43.30 then significantly increased by $8.10 \%, 11.53 \%, 13.31 \%, 14.48 \%$, $15.10 \%$ respectively at a current of $0.75,1.00,1.25$, and $1.5 \mathrm{~A}$. At zone 2 , the current $0.25 \mathrm{~A}$ was $42.90 \mathrm{KPa}$ and $8.69 \%, 12.39 \%, 14.47 \%, 15.66 \%$ and $16.26 \&$ respectively at current of $0.75,1.00,1.25$, and 1.5 A. However, in this simulation result, shear yield stress can significantly increase with the increase of current. Those results shown that MRF surrounds device performance is acceptable. So that further research should be done to investigate the damping force on the surrounding device of loudspeakers shown in Figure 1.

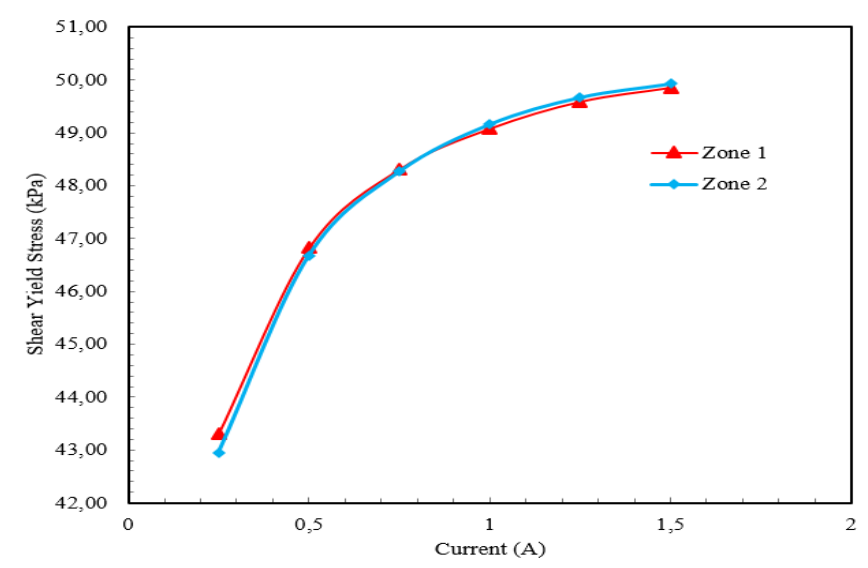

Figure 7. Changes of the shear yield stress of the MRF

\subsection{Experimental Test}

The loudspeaker MRF was tested in a cubic chamber with $800 \mathrm{~mm}$ sides. On each side of the chamber covered with a coated damper foam and it has been ensured that the layer has been designed tightly without. Testing equipment utilizes an amplifier which is connected to open source software (online tone generator). Figure 8 shows the results of the sine wave spectrum at a frequency range of $43.06 \mathrm{~Hz}$ to $22006.93 \mathrm{~Hz}$ and a sound level of $51 \mathrm{~dB}$ up to $96 \mathrm{~dB}$. The current input shown in Figure 8, produces a damping force on both sides of the loudspeaker surround layer. By adjusting the current on the loudspeaker MRF coil, it proves that the behavior of the sound spectrum variation can be explained. The current increase while the sound level spectrum on the sound level decreases, due to the damping force that holds back the surround movement to muffle the sound. Besides, the stiffness of the surround material increases as the increase of magnetic flux. These results are important and interesting to study and do on various frequencies.

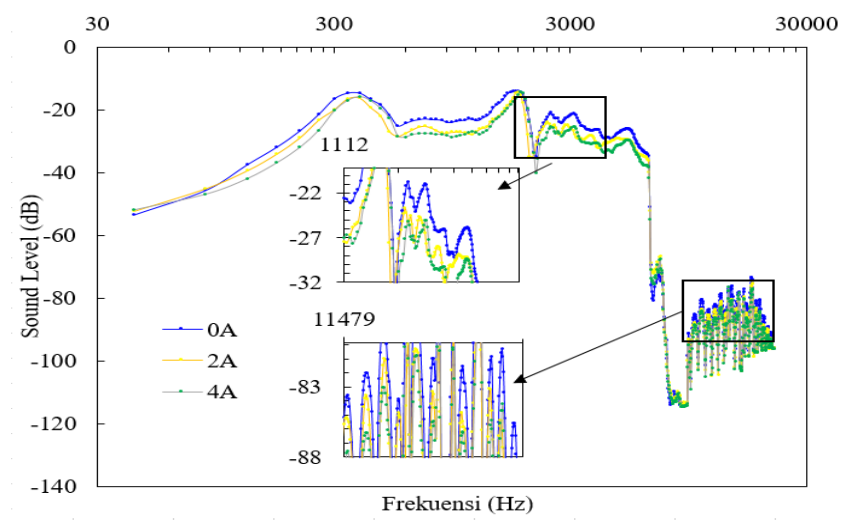

Figure 8. Sine wave spectrum of MRF loudspeaker experimental test 


\section{CONCLUSION}

A novel design of an MRF device of loudspeaker surround damping system has been presented. The performances of a MRF loudspeaker absorber have been experimentally evaluated. The aim of modification of the loudspeaker surround by replacing conventional rubber to MRF based damper was to make the tunable loudspeaker output. The whole works were successful in achieving such aim. Step by step design was properly presented and preliminary experimental evaluation was succes. The simulation result shows that the minimum current of 0.25 A could change the yield stress of MRF in zone 1 and 2 was up to 43 and $42.9 \mathrm{kPa}$, respectively. Moreover, shear yield stress was predicted to be 49.90 and $49.95 \mathrm{kPa}$ at 1.5 . A current applied correspond to each zone. Therefore, the value of shear yield stress increased $15,10 \%$ on zone 1 which was higher than zone 2. The final design of MRF based loudspeaker surround has been realized in a working prototype. The preliminary experimental evaluation show that the output of loudspeaker can be tuned by $3 \mathrm{~dB}$ when the magnetic flux was applied into the system. This achievement would be a promising future research of MRF based loudspeaker surround.

\section{ACKNOWLEDGEMENT}

This research was financially supported by Hibah Mandatory 2019, Universitas Sebelas Maret, and partial funding from SHERA Project through Prime Award: AID-497- A-16- 00004.

\section{REFERENCES}

[1] K. Raj, B. Moskowitz, R. Casciari, "Advances in ferrofluid technology," Journal of Magnetism and Magnetic Materials, Elsevier., vol. 149, no. 1-2, pp. 174-180, Aug 1995.

[2] X.-P. Kong, X.-W. Zeng, and K.-F. Han, "Dynamical Measurements on Viscoelastic Behaviors of Spiders in Electro-Dynamic Loudspeakers,” Appl. Acoust., vol. 104, pp. 67-75, 2016.

[3] P. E. Kuntz, United States Patent (19), no. 19, 1994.

[4] Lord Product Selector Guide, "Lord product selector guide lord Magneto-Rheological Fluids," vol. 130, pp. 0-1.

[5] S. A. A. Aziz, et al., "Effects of multiwall carbon nanotubes on viscoelastic properties of magnetorheological elastomers," Smart Mater. Struct., vol. 25, no. 7, pp. 1-10, 2016.

[6] A.Z.B. Pokaad, K. Hudha, M.Z.B.M. Nasir and Ubaidillah, "Simulation and experimental studies on the behaviour of a magnetorheological damper under impact loading," International Journal of Structural Engineering, vol. 2, no. 2, pp. 164-187, 2011.

[7] N.A.A. Wahab, S. A. Mazlan, Ubaidillah, A. Kamaruddin, N.I.N. Ismail, S.B. Choi and A.H.R. Sharif, "Fabrication and investigation on field-dependent properties of natural rubber based magneto-rheological elastomer isolator," Smart Mater. Struct., vol. 25, no. 10, pp. 107002, 2016.

[8] S.-B. Choi, M.-H. Nam, and B.-K. Lee, "Vibration control of a MR seat damper for commercial vehicles," Journal of Intelligent Materials Systems and Structures, vol. 11, no. 12, pp. 936-944, 2000.

[9] H. Du, W. Li, and N. Zhang, "Semi-active variable stiffness vibration control of vehicle seat suspension using an MR elastomer isolator," Smart Materials and Structures, vol. 20, no. 10, 2011.

[10] H. J. Jung, B. F. Sodeyama, Y. Q. Ni, et al., "State-of-the-art of semiactive control systems using MR fluid dampers in civil engineering applications, " Structural Engineering and Mechanics, vol. 17, no. 3-4, pp. 493-526, 2004.

[11] B. F. Spencer and S. Nagarajaiah, "State of the art of structural control," Journal of structural engineering, vol. 129, no. 7, pp. 845-856, 2003.

[12] G. Aydar, "A new magneto-rheological fluid (MRF) washing machine damper and a novel two-way-controllable MRF valve," Ph.D. dissertation, University of Nevada, Reno, NV, USA, 2007.

[13] C. Spelta, F. Previdi, S. M. Savaresi, G. Fraternale, and N. Gaudiano, "Control of magnetorheological dampers for vibration reduction in a washing machine," Mechatronics, vol. 19, no. 3, pp. 410-421.

[14] J. C. Poynor, "Innovative designs for magneto-rheological dampers," Master's thesis, Virginia Polytechnic Institute and State University, Blacksburg, VA, USA, 2001.

[15] J. D. Carlson, W. Matthis, and J. R. Toscano, "Smart prosthetics based on magnetorheological fluids," Smart Structures and Materials 2001: Industrial and Commercial Applications of Smart Structures Technologies, International Society for Optics and Photonics, Bellingham, WA, USA, vol. 4332, pp. 308-317, Jun 2001.

[16] D. Y. Lee, Y. J. Nam, R. Yamane et al., "Performance evaluation on vibration control of MR landing gear," Journal of Physics: Conference Series, vol. 149, 2009.

[17] M. Khani, "Magneto-rheological (MR) damper for landing gear system," Ph.D. dissertation, Concordia University, Montreal, Canada, 2010.

[18] S. Dutta and S. B. Choi, "A nonlinear kinematic and dynamic modeling of Macpherson suspension systems with a magneto-rheological damper," Smart Materials and Structures, vol. 25, no. 3, 2016.

[19] B. Ebrahimi, "Development of hybrid electromagnetic dampers for vehicle suspension systems," Ph.D. dissertation, University of Waterloo, Waterloo, Canada, 2009.

[20] B. Heißing and M. Ersoy, Chassis Handbook, Springer Science \& Business Media, Berlin, Germany, 2010.

[21] J. H. Park, W. H. Kim, C. S. Shin, et al., "A comparative work on vibration control of a quarter car suspension system withtwo different magneto-rheological dampers, "Smart Materials and Structures, vol. 26, no. 1, 2016. 
[22] N. M. Wereley, W. Hu, C. S. Kothera et al., "Magnetorheological fluid elastic lag damper for helicopter rotors," US Patent Application, no. 8,413,772, 2013.

[23] A. Milecki and M. Hauke, "Application of magnetorheological fluid in industrial shock absorbers," Mechanical Systems and Signal Processing, vol. 28, pp. 528-541, 2012.

[24] Q.-H. Nguyen, S.-B. Choi, and N. M. Wereley, "Optimal design of magnetorheological valves via a finite element method considering control energy and a time constant," Smart Mater. Struct., vol. 17, no. 2, pp. 25024, 2008.

[25] T. Lee, J. Yoon, S. Shin, and S. Choi, "a development of new type speaker featuring variable resonant frequencies by utilizing a magneto-rheological foam,” pp. 1-4. 2017.

[26] Ubaidillah et al., "A new class of magnetorheological elastomers based on waste tire rubber and the characterization of their properties," Smart Mater. Struct., vol. 25, no. 11, pp. 1-15, 2016.

[27] $\mathrm{Li}$, Yancheng, Jianchun $\mathrm{Li}$, Weihua $\mathrm{Li}$, and Haiping Du, "A state-of-the-art review on magnetorheological elastomer devices." Smart materials and structures, vol. 23, no. 12, pp. 123, 2014.

[28] Kaluvan, S., H. C. Kim, J. S. Oh, and S. B. Choi, "A State-of Art of Creative Sensor Devices Utilizing MagnetoRheological Fluids," Int J Mech Syst Eng, vol. 1, no. 108 pp. 2, 2015. 